\title{
CONTROLE QUÍMICO DA LOSNA EM PLANTIO DIRETO DE TRIGO
}

\author{
ALEXANDRE M. BRIGHENTI ${ }^{2}$, JOSÉ F. DA SILVA ${ }^{2}$, NEI F. LOPES ${ }^{4}$, ANTONIO A. CARDOSO ${ }^{5}$ \\ e LINO R. FERREIRA ${ }^{6}$
}

\begin{abstract}
A losna (Artemisia verlotorum) é uma planta daninha com alta capacidade de rebrota de seus rizomas e tolerante à maioria dos herbicidas, principalmente os de contato, o que dificulta consideravelmente o seu controle químico e mecânico. Areas naturalmente infestadas com essa planta foram tratadas com glifosate e 2,4-D, em diferentes doses combinadas entre si. O glifosate foi mais eficiente que o 2,4-D. O 2,4-D não apresentou efeito sobre a losna aos 90 dias após sua aplicação. $\mathrm{O}$ glifosate apresentou um efeito mais prolongado que o 2,4-D, reduzindo o número de plantas vivas até os 90 dias após sua aplicação. A aplicação das doses inter
\end{abstract}

RESUMO

mediárias proporcionou um controle mais eficiente da losna em detrimento do uso de doses mais elevadas. Os valores máximos alcançados pelas características avaliadas na cultura do trigo coincidiram com a aplicação de doses intermediárias, que proporcionaram o melhor controle da losna. Mais rendimento do trigo $(3787 \mathrm{~kg} / \mathrm{ha})$ foi obtido quando se efetuou a aplicação da mistura de $0,721 \mathrm{~kg} / \mathrm{ha}$ de glifosate com 1,152 kg/ha de 2,4-D.

Palavras-chave: invasoras perenes, herbicidas sistêmicos, Artemisia verlotorum.

\section{ABSTRACT}

\section{Chemical control of wormwood in no-tillage wheat}

It is difficult to obtain an efficient mechanical and chemical control of wormwood (Artemisia verlotorum) because this weed has a great capacity to sprout and is tolerant to most herbicides. Natural areas infested with wormwood were treated with glyphosate and 2,4-D. Glyphosate was more efficient than 2,4-D on wormwood control. The application of 2,4-D did not cause significant differences on wormwood control 90 days after treatment. However, the glyphosate had prolonged effect, decreasing the number of

\section{INTRODUÇÃO}

A losna (Artemisia verlotorum Lamotte) pertence à família das Compositae e é, provavelmente, originária da Europa ou da Asia (Corrêa, 1984). E uma planta daninha

\footnotetext{
${ }^{1}$ Recebido para publicação em 16/03/93 e na forma revisada em 05/06/93.

Parte de Dissertação de Mestrado do primeiro autor.

${ }^{2} \mathrm{Eng}^{\circ} \mathrm{Agr}^{\circ}, \mathrm{MSc}$

${ }^{3}$ Eng $^{\circ}$ Agr $^{\circ}$, PhD, Depto de Fitotecnia, UFV, 36570-000 Viçosa, MG

${ }^{4} \mathrm{Eng}^{\circ} \mathrm{Agr}^{\circ} \mathrm{PhD}$, Depto de Biologia Vegetal, UFV, 36570-000 Viçosa, MG

${ }^{5}$ Eng $^{\circ}$ Agr $^{\mathrm{a}}$, DS, Depto de Fitotecnia, UFV, 36570-000 Viçosa, MG

${ }^{6} \mathrm{Eng}^{\circ} \mathrm{Agr}^{\circ}$, MSc, Depto de Fitotecnia, UFV, 36570-000 Viçosa, MG
}

living plants until 90 days after its application. Intermediary rates were more effecient than higher rates on wormwood control. Higher values of all studied characteristics of wheat crop were obtained with intermediary rates of both herbicides. Higher yield of wheat $(3787 \mathrm{~kg} / \mathrm{ha})$ were obtained when $0,721 \mathrm{~kg} / \mathrm{ha}$ of glyphosate associated with $1,152 \mathrm{~kg} / \mathrm{ha}$ of 2,4-D was applied.

Additional index words: perennial weeds, systemic herbicides, Artemisia verlotorum.

tanto de solos cultivados quanto de jardins, pastagens e beiradas de estradas. E perene, herbácea e rizomatosa. Sua importância como invasora vem aumentando no Sul e Sudeste do Brasil, graças à sua eficiente capacidade reprodutiva. Talvez seja a planta detentora de maior vigor reprodutivo por meios vegetativos, podendo produzir até $5 \mathrm{t} / \mathrm{ha}$ de matéria seca de rizomas, os quais, além de se propagarem e se reproduzirem a certa distância da planta mãe, servem também como depósito de reservas nutritivas (Lorenzi, 1982).

A capina manual e o cultivo mecânico não reduzem a competição imposta pela losna, por causa de sua grande 
capacidade de formar uma massa vegetativa subterrânea (rizomas), que continua competindo com a cultura, mesmo após a remoção de sua arte aérea.

A medida que plantas daninhas predominantes vão sendo controladas quimicamente, outras, anteriormente menos importantes, mas tolerantes aos herbicidas utilizados, passam a ser predominantes no agroecossistema modificado. Num sistema agrícola, em que a monocultura é predominante, o fato de serem utilizados continuamente os mesmos herbicidas causa modificações na flora nativa, permane cendo as espécies mais resistentes, como a losna.

Esta planta daninha tem se mostrado tolerante à maioria dos herbicidas utilizados, principalmente nas culturas de milho e soja, propagando-se rapidamente.

Este trabalho teve como objetivo avaliar o efeito de herbicidas sobre a losna, visando a controlar suas estruturas vegetativas, num sistema de plantio direto.

\section{MATERIAL E MÉTODOS}

O experimento foi instalado em uma área uniformemente infestada com losna, em Coimbra, MG, situada a uma latitude $20^{\circ} 50^{\prime} 30^{\prime \prime} \mathrm{S}$ e longitude $42^{\circ} 48^{\prime} 30^{\prime \prime} \mathrm{W}$, durante o período de 18 de maio a 18 de setembro de 1991 . 0 solo era um podzólico vermelho-amarelo, apresentando textura argilosa com 7\% de areia grossa, $7 \%$ de areia fina, $27 \%$ de silte, $59 \%$ de argila, 2,1\% de matéria orgânica e pH 6,4.

Foram utilizados 16 tratamentos provenientes da combinação de 4 doses $(0,0,384,0,768$ e $1,152 \mathrm{~kg} / \mathrm{ha})$ do ingrediente ativo do herbicida glifosate (Roundup) e 4 doses $(0$, $0,576,1,152$ e $1,728 \mathrm{~kg} / \mathrm{ha}$ ) do ingrediente ativo do herbicida 2,4-D (U-46 D Fluid), num delineamento inteiramente casualizado, em arranjo fatorial $4 \times 4$, com 4 repetições.

A aplicação dos herbicidas foi feita em parcelas de 12 $\mathrm{m}^{2}$ com um pulverizador costal manual, com capacidade para 20 litros, calibrado com uma pressão aproximada de
206,8 kPa, dando uma vazão de 250 1/ha, quando a losna tinha aproximadamente $20 \mathrm{~cm}$ de altura.

Aos 5 dias após a aplicação dos herbicidas (DAAH), foi realizado o plantio direto de trigo (cultivar BR-26 São Gotardo). Utilizou-se uma plantadeira (Jumil 2611) com 11 linhas de plantio distanciadas de $17 \mathrm{~cm}$ e regulada para 70 sementes por metro linear. A adubação inicial foi de 350 $\mathrm{kg} / \mathrm{ha}$ da fórmula 4-14-8 e $75 \mathrm{~kg} / \mathrm{ha}$ de sulfato de amônio aos 15 dias após o plantio, distribuído a $5 \mathrm{~cm}$ da fileira da cultura. $\mathrm{O}$ trigo foi irrigado por aspersão, mantendo-se o solo na capacidade de campo.

A ação dos herbicidas sobre a losna foi avaliada determinando-se o número de plantas vivas aos 30,60 e 90 após a sua aplicação. As amostragens foram realizadas em áreas de $0,25 \mathrm{~m}^{2}$ situadas nas regiões centrais das parcelas.

Foi determinada a altura média das plantas de trigo, medindo-se 20 plantas ao acaso em cada parcela.

Foram determinados também o número de espigas e o peso da matéria seca de plantas e espigas de trigo. O peso da matéria seca foi obtido colocando-se a matéria verde em uma estufa de ventilação forçada por $48 \mathrm{~h}$ a $75^{\circ} \mathrm{C}$.

Após trilhagem, foi determinado o peso de 1000 sementes de trigo e, em seguida, a produção de grãos por parcela em uma área de $1 \mathrm{~m}^{2}$, sendo ambos corrigidos para $13 \%$ de umidade.

\section{RESULTADOS E DISCUSSÃO}

A maior eficiência de controle da losna aos 30 dias após a aplicação dos herbicidas (DAAH) ocorreu com a aplicação do 2,4-D junto com as doses 0,0;0,768 e 1,152 $\mathrm{kg} / \mathrm{ha}$ do glifosate (Figura 1A). Detectou-se efeito significativo da interação. Da mesma forma, a dose $0,576 \mathrm{~kg} / \mathrm{ha}$ do 2,4-D misturada às doses do glifosate proporcionou um bom controle da losna (Figura 1B). A dose $0,768 \mathrm{~kg} / \mathrm{ha}$ de glifosate combinada com $1,450 \mathrm{~kg} / \mathrm{ha}$ de $2,4-\mathrm{D}$ proporcionou
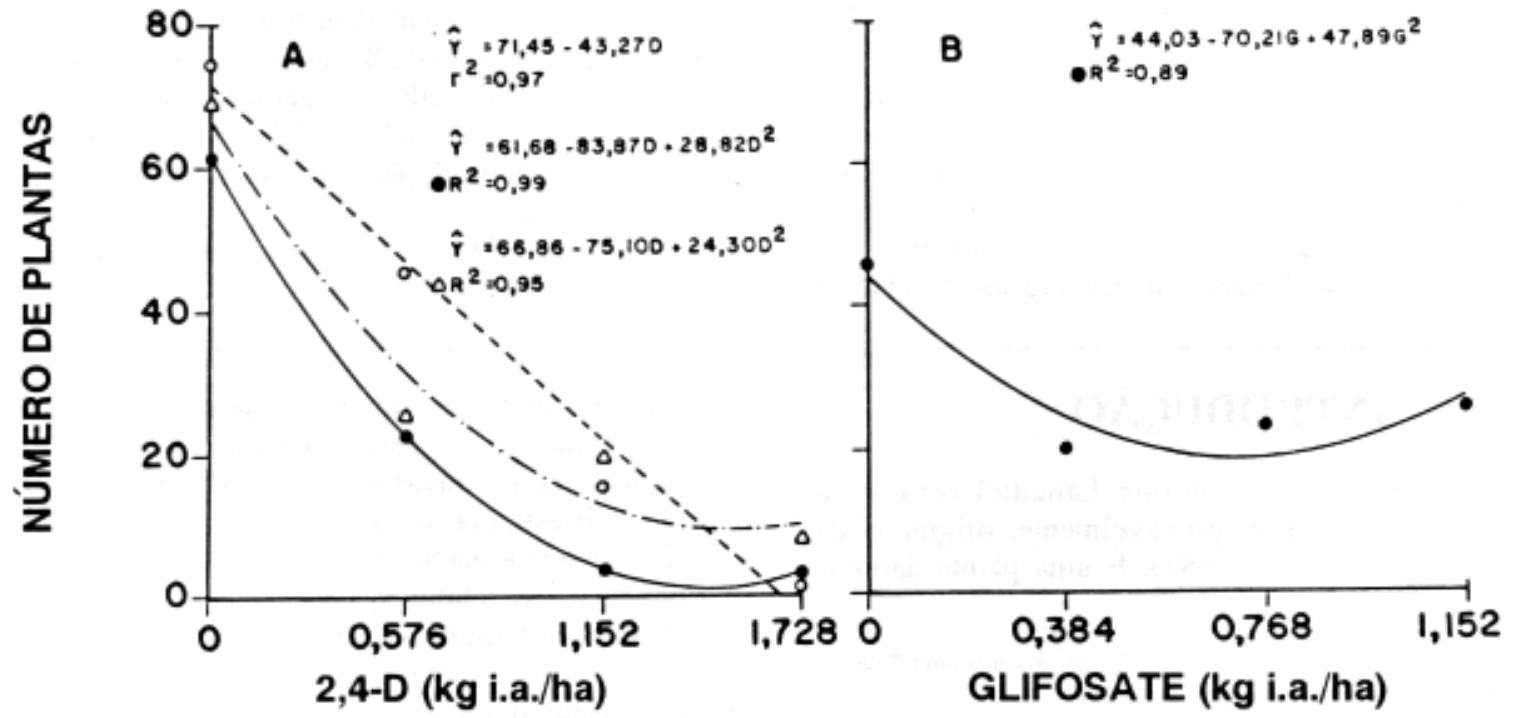

FIG. 1 - Número de plantas vivas de losna aos 30 dias após a aplicação de 2,4-D, associado às doses de 0,0 ( $\mathrm{O}---)$, $0,768(-)$ e $1,152(\Delta-\cdot-) \mathrm{kg} / \mathrm{ha}$ do ingrediente ativo do glifosate (A) e do glifosate combinado com 0,576 (O) $\mathrm{kg} / \mathrm{ha} \mathrm{de} \mathrm{2,4-D} \mathrm{(B).}$ 
melhor controle desta planta daninha aos 30 DAAH que $1,152 \mathrm{~kg} / \mathrm{ha}$ do glifosate com 1,540 kg/ha do 2,4-D (Figura 1A). Provavelmente, os dois herbicidas, quando aplicados em doses mais elevadas, danificaram os vasos condutores, afetando a translocação dos produtos na planta (Klingman, 1961; Sprankle et al., 1975). Um controle satisfatório da losna foi obtido também com aplicação de $0,576 \mathrm{~kg} / \mathrm{ha}$ do 2,4-D combinado com $0,733 \mathrm{~kg} /$ ha do glifosate (Figura 1B). Resultados similares foram obtidos por Santos et al. (1991).

A melhor eficiência de controle da losna aos 60 DAAH ocorreu com a utilização dos herbicidas aplicados isoladamente. O 2,4-D, na dose $1,240 \mathrm{~kg} / \mathrm{ha}$, reduziu o número de plantas vivas de 65 para 40 (Figura $2 \mathrm{~A}$ ), enquanto que o glifosate, na dose $0,886 \mathrm{~kg} / \mathrm{ha}$, reduziu o número de plantas vivas de 105 para 18 (Figura 2B).

Um bom controle da losna foi verificado aos 90 DAAH quando o glifosate, aplicado na dose $1,048 \mathrm{~kg} / \mathrm{ha}$, reduziu o número de plantas vivas de 85 para 16 (Figura 3 ).
Não se verificou mais o efeito da metabolização do produto pela planta daninha.

Houve um maior peso da matéria seca das plantas de trigo quando se utilizou os dois herbicidas aplicados isoladamente. $\mathrm{O}$ aumento das doses dos dois produtos acarretou diminuição da competição das plantas daninhas, proporcionando um maior crescimento e um maior peso da maté ria seca da parte aérea do trigo. Esse aumento atingiu um máximo, a partir do qual as doses mais elevadas, possivelmente, prejudicaram a translocação dos produtos na losna, reduzindo a eficiência de controle. Esses valores máximos foram estimados pelas equações de regressão: $3311 \mathrm{~kg} / \mathrm{ha}$ com $1,144 \mathrm{~kg} / \mathrm{ha}$ de 2,4-D e $2601 \mathrm{~kg} / \mathrm{ha}$ com $0,845 \mathrm{~kg} / \mathrm{ha} \mathrm{de}$ glifosate (Figuras 4A e 4B).

$\mathrm{O}$ peso da matéria seca se espigas do trigo foi maior quando o 2,4-D e o glifosate foram aplicados isoladamente. Melhor controle da losna foi obtido quando se aumentaram as doses dos dois produtos, o que acarretou um aumento da
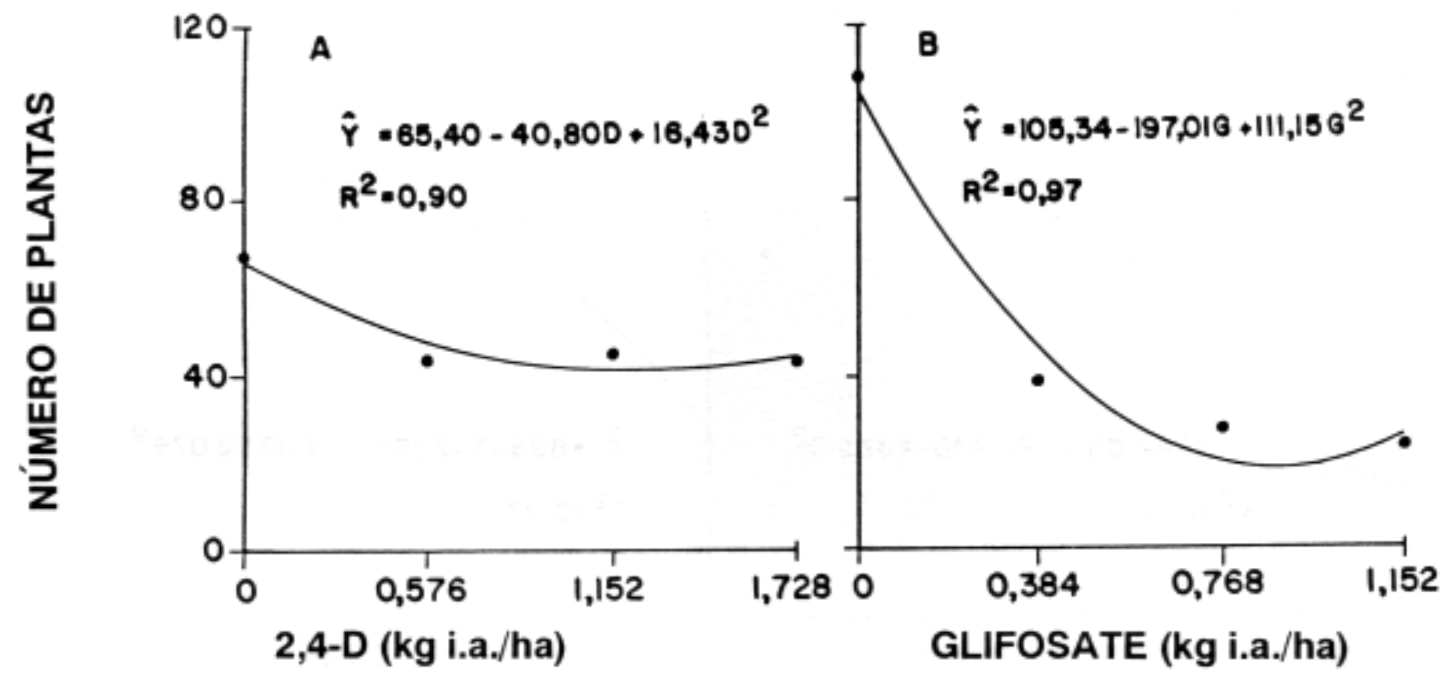

FIG. 2 - Número de plantas vivas de losna aos 60 dias após a aplicaçảo de 2,4-D (A) e de glifosate (B).

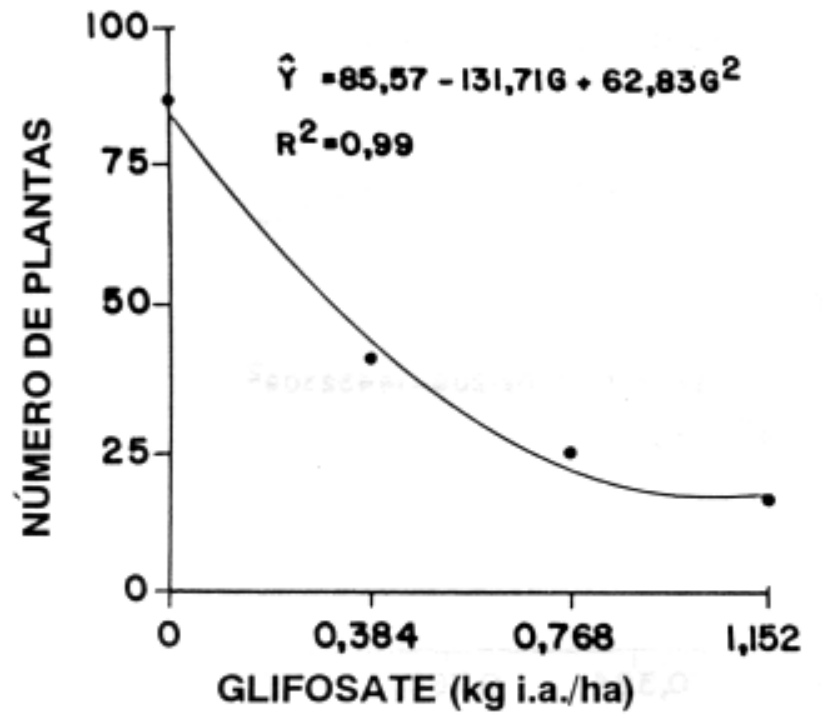

FIG. 3 - Número de plantas vivas de losna aos 90 dias após a aplicaçẩo de glifosate. matéria seca das espigas do trigo até atingir valores máximos: $1541 \mathrm{~kg} / \mathrm{ha} \mathrm{com} 1,131 \mathrm{~kg} / \mathrm{ha}$ de $2,4-\mathrm{D}$, e $1660 \mathrm{~kg} / \mathrm{ha}$ com $0,845 \mathrm{~kg} / \mathrm{ha}$ de glifosate (Figuras $5 \mathrm{~A}$ e $5 \mathrm{~B}$ ).

$\mathrm{O}$ número de espigas de trigo aumentou com a aplicação de doses maiores dos dois herbicidas, atingindo um valor máximo, que coincidiu com o melhor controle da losna na cultura do trigo. Estes valores, estimados a partir das equações de regressão, foram: 2557934 espigas/ha com 1,258 $\mathrm{kg} / \mathrm{ha}$ de 2,4-D; e 2635039 espigas/ha com 0,693 kg/ha do glifosate (Figuras 6A e 6B).

$\mathrm{O}$ peso de mil sementes de trigo foi beneficiado pela utilização de ambos os herbicidas aplicados isoladamente (Figuras 7A e 7B). Verificou-se um aumento linear dessa característica com o aumento das doses de 2,4-D. Entretanto, com o glifosate, o maior peso de mil sementes (39,37 gramas) foi obtido com a aplicação de $0,867 \mathrm{~kg} / \mathrm{ha}$ (Figura 7B).

A altura de plantas do trigo foi favorecida pela aplicação de glifosate associado a 2,4-D (Figura 8), sendo observado efeito significativo da interação dos dois produtos. A maior altura das plantas foi obtida quando se aplicou a com- 


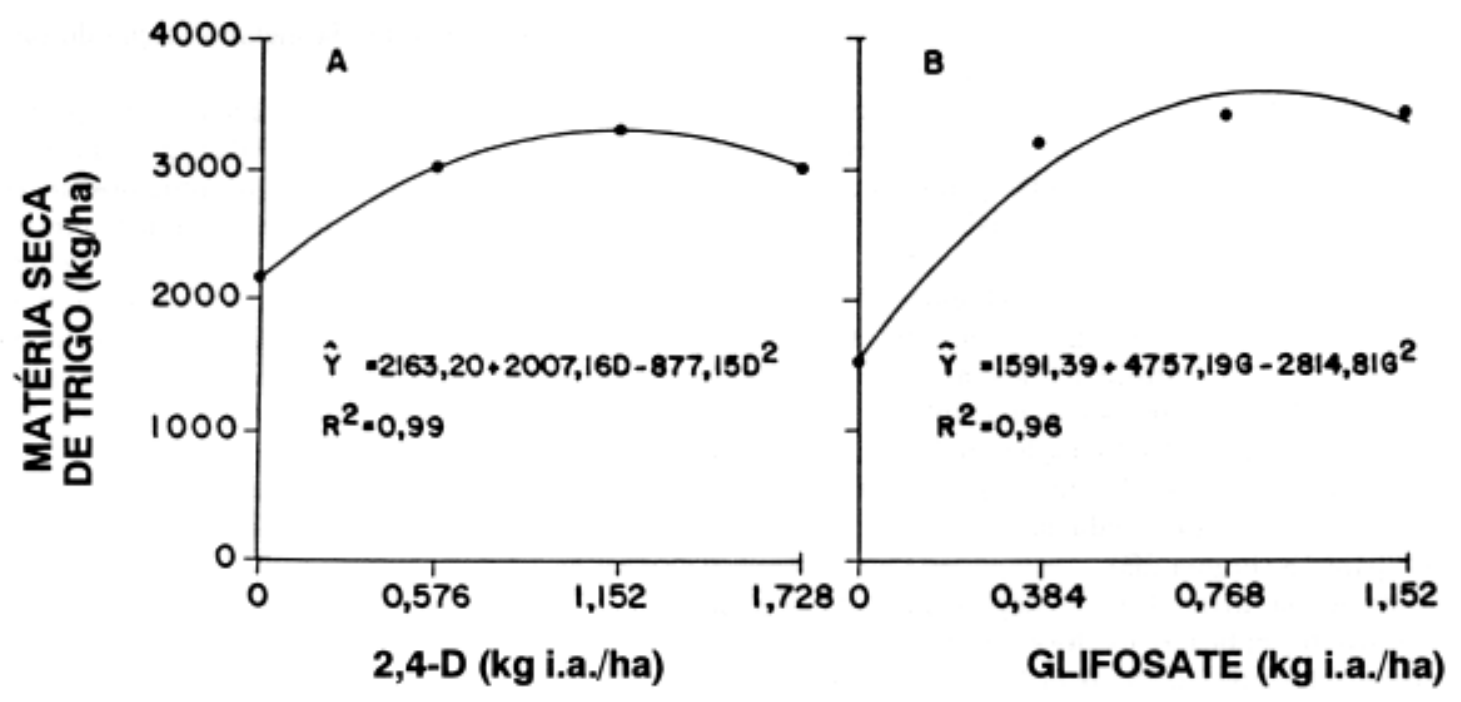

FIG. 4 - Peso da matéria seca de plantas de trigo após a aplicaçảo de 2,4-D (A) e de glifosate (B).
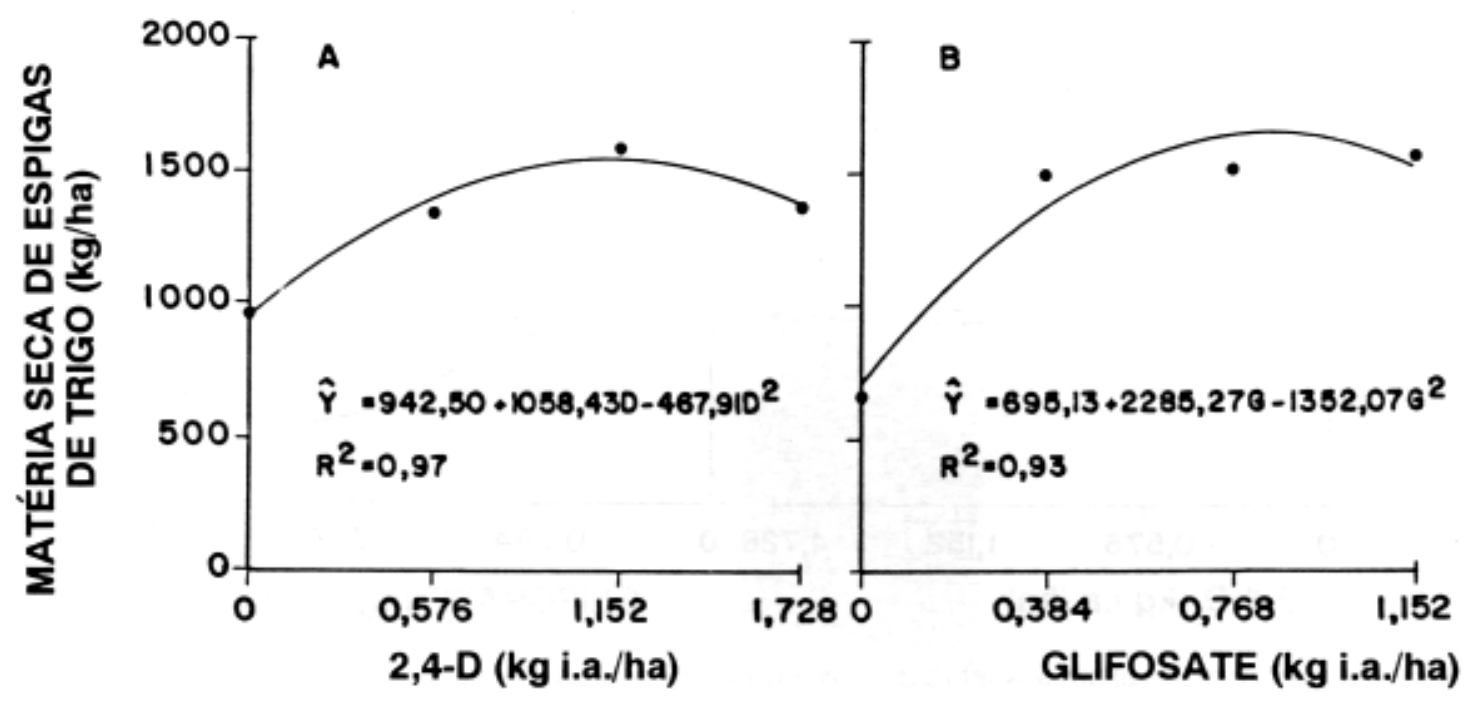

FIG. 5 - Peso da matéria seca de espigas de trigo após a aplicaçāo de 2,4-D (A) e de glifosate (B).
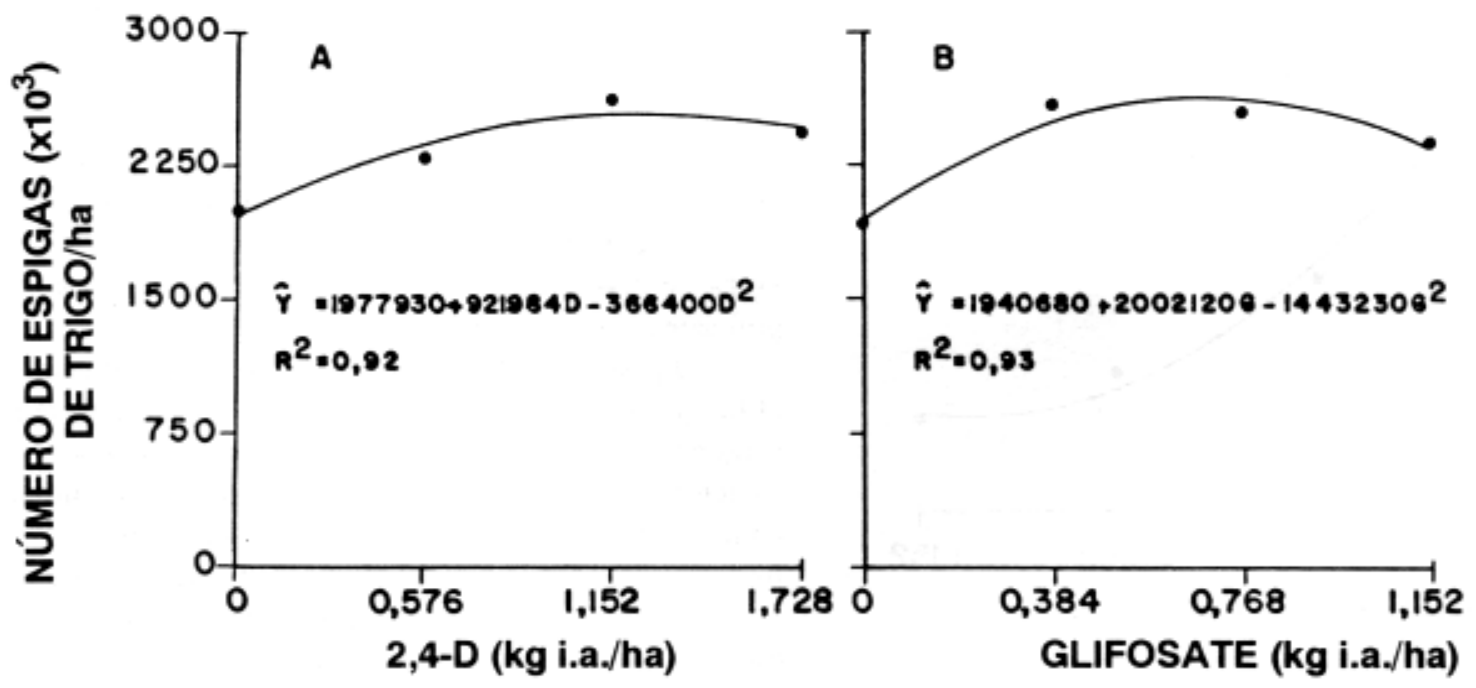

FIG. 6 - Número de espigas de trigo após a aplicaçảo de 2,4-D (A) e de glifosate (B). 

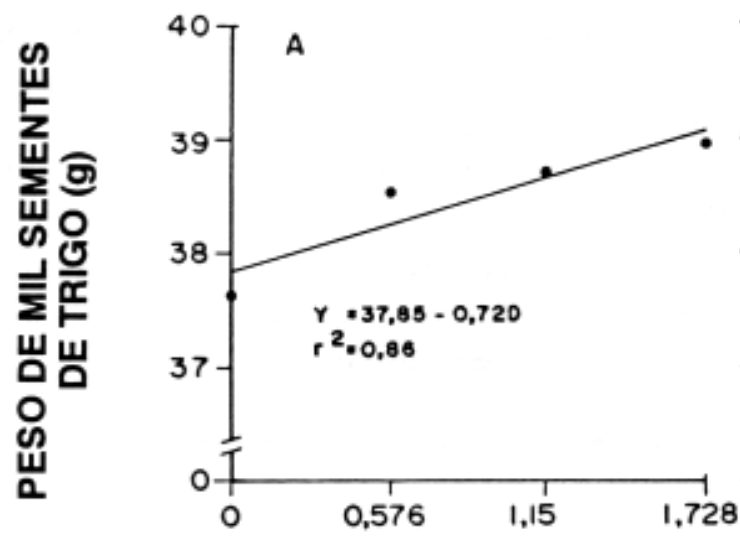

2,4-D (kg i.a./ha)

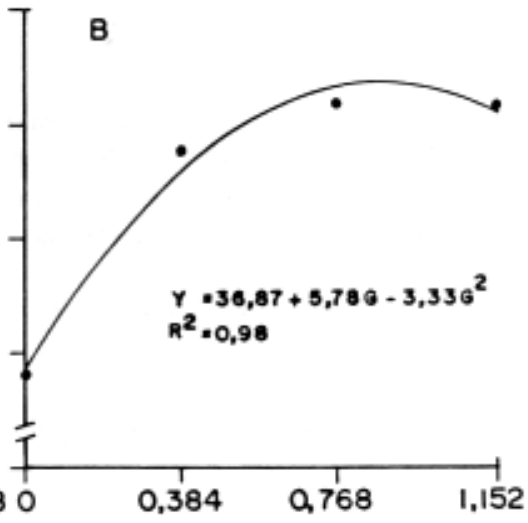

GLIFOSATE (kg i.a./ha)

FIG. 7 - Peso de mil sementes de trigo após a aplicaçảo de 2,4-D (A) e de glifosate (B).

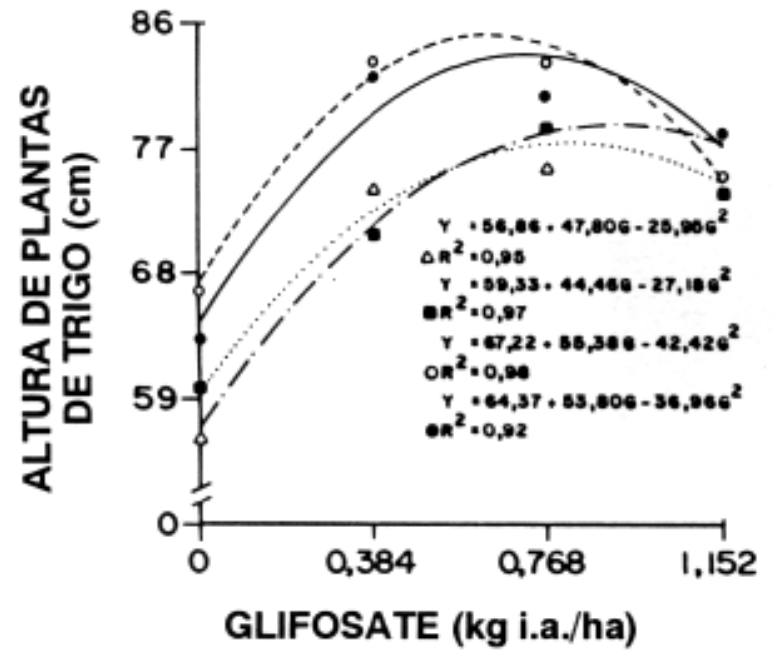

FIG. 8 - Altura de plantas de trigo após a aplicaçäo de glifosate associadas às doses de $0,0(\Delta-\cdot-), 0,576(\square \cdots), 1,152(\mathrm{O}--)$ e $1,728(-)$ $\mathrm{kg} / \mathrm{ha} \mathrm{de} \mathrm{2,4-D.}$
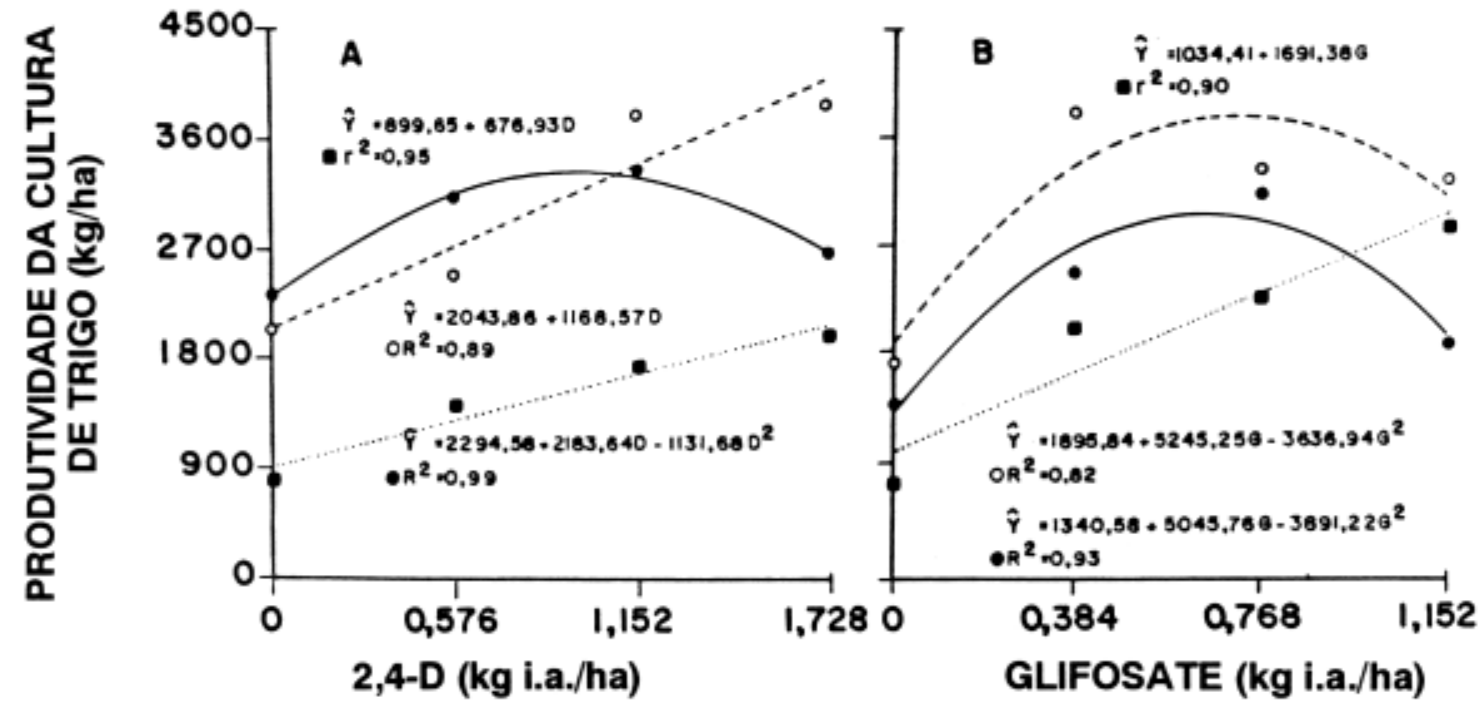

FIG. 9 - Produtividade da cultura de trigo após a aplicaçăo das doses de 2,4-D associadas às doses de $0,0(\square \cdots), 0,384$ $(\mathrm{O}--)$ e $0,768(-) \mathrm{kg} / \mathrm{ha}$ de glifosate $(\mathrm{A})$, e de glifosate combinado com as doses de $0,0(\square \cdots), 0,576$ (-) e 1,152 (O--) kg/ha de 2,4-D (B). binação de $1,152 \mathrm{~kg} / \mathrm{ha}$ de 2,4-D com $0,652 \mathrm{~kg} / \mathrm{ha}$ do glifosate.

A produtividade da cultura de trigo foi incrementada quando se aplicou somente o 2,4-D (Figura 9A), e quando se utilizou as misturas de 0,384 e $0,768 \mathrm{~kg} / \mathrm{ha}$ do glifosate com as doses do 2,4-D. Foi observado o efeito significativo da interação dos dois herbicidas. Obtiveram-se $3347 \mathrm{~kg} / \mathrm{ha}$ de trigo com a aplicação e $0,768 \mathrm{~kg} / \mathrm{ha}$ de glifosate associado a 0,964 kg/ha de 2,4-D. A produção aumentou quando se utilizou o glifosate isolado (Figura 9B) e quando combinado com 0,576 e 1,152 kg/ha de 2,4 D. A produtividade foi $2976 \mathrm{~kg} / \mathrm{ha}$, quando se misturou $0,576 \mathrm{~kg} / \mathrm{ha}$ do $2,4-\mathrm{D}$ com $0,648 \mathrm{~kg} / \mathrm{ha}$ do glifosate, e $3787 \mathrm{~kg} / \mathrm{ha}$ de trigo quando se aplicou $0,721 \mathrm{~kg} / \mathrm{ha}$ de glifosate com 1,152 kg/ha do 2,4-D. 


\section{LITERATURA CITADA}

CORREAA, M.P. Dicionário de plantas úteis do Brasil. Rio de Janeiro: Ministério da Agricultura, 1984. 41p.

LORENZI, H. Plantas daninhas do Brasil: terrestres, aquáticas, parasitas, tóxicas e medicinais. Nova Odessa, SP: ed. do autor, 1982.425p.

KLINGMAN, G.C. Weed control: as a science. New York: John Wiley \& Sons, 1961.421p.
SPRANKLE, P.; MEGGITT, W.F.; PENNER, D. Absorption, action and translocation of glyphosate. Weed Science, v.23, n.3, p.235-240, 1975.

SANT OS, A.M.B.; SILVA, J.F.; FERREIRA, L.R.; CARDOSO, A.A. Controle químico da losna (Artemisia verlotorum Lamotte); In: Congresso Brasileiro de Herbicidas e Plantas Daninhas, 18., Brasília, DF. Resumos. Brasília: SBHED, 1991. 124p. 